\title{
Mathematical Modeling of Hydrogen Production Process by Pressure Swing Adsorption Method
}

\author{
E.I. Akulinin ${ }^{1 *}$, A.A. Ishin ${ }^{2}$, S.A. Skvortsov ${ }^{2}$, D.S. Dvoretsky ${ }^{1}$, S.I. Dvoretsky ${ }^{1}$ \\ ${ }^{1}$ Department of Technology and Equipment for Food and Chemical Production, \\ ${ }^{2}$ Department of Information Processes and Management, Tambov State Technical University, \\ 1, Leningradskaya St., Tambov, 392000, Russia
}

* Corresponding author: Tel.:+7(909) 23140 61; E-mail: akulinin-2006@yandex.ru

\begin{abstract}
A mathematical model of the dynamics of pressure swing adsorption (PSA) process during separating multicomponent gas mixtures to produce hydrogen has been developed. The model includes the equations of mass- and heat transfer processes which occur during adsorption (desorption) of the components $\left(\mathrm{H}_{2}, \mathrm{CO}_{2}\right.$ и $\left.\mathrm{CO}\right)$ of gas mixture by granular zeolite adsorbents $\mathrm{CaA}, \mathrm{NaX}$, LiLSX; the equation of the kinetics of mixed-diffusive transport of adsorbate $\left(\mathrm{H}_{2}, \mathrm{CO}_{2}\right.$ и $\left.\mathrm{CO}\right)$; the LangmuirFreundlich isotherm equation for multicomponent gas mixtures; the Ergun equation for calculating the pressure and velocity of gas mixture in the adsorber, and allows calculating the profiles of component concentrations $\left(\mathrm{H}_{2}, \mathrm{CO}_{2}\right.$ и $\left.\mathrm{CO}\right)$ and temperature in the gas and solid phases, pressure and velocity of the gas mixture along the height of the adsorbent depending on time. As a result of computational experiments, the effect of changes in the temperature, composition, and pressure of the initial gas mixture on the purity, recovery, and production hydrogen temperature at multiple duration periods of the adsorption stage was determined. The dynamics of the adsorption process of gas mixture components and the character of sorption and thermal fronts motion along the height of the adsorbent bed in the adsorber, as well as the relationship between the output of the 4-column PSA unit and the purity of the produced hydrogen have been studied.
\end{abstract}

\section{Keywords}

Adsorption isotherm; carbon dioxide; gas mixture; hydrogen; mathematical model; pressure swing adsorption; zeolites.

(C) E.I. Akulinin, A.A. Ishin, S.A. Skvortsov, D.S. Dvoretsky, S.I. Dvoretsky, 2017

\section{Introduction}

In recent decades, it has become increasingly common to use cyclic adsorption processes to separate gas mixtures and concentrate target products in them. The adsorption process is the interaction of a bulk phase (gas or liquid) and an adsorbent, during which certain components of the bulk phase are absorbed by the adsorbent; at the output, a concentrated product is obtained, which is the least sorbing component. The adsorption processes with regenerated adsorbent include processes with direct and indirect heat input, and heatless processes. Short-cycle heatless adsorption (called Pressure Swing Adsorption in the Englishlanguage literature) represents a special class of adsorption processes. As the name implies, PSA processes do not imply the presence of an external heat source. Due to high rates of adsorption-desorption, compared to heat transfer processes, the heat loss with production gas flow is minimal; thus, the heat released at the adsorption stage is used to desorb the adsorbed components during the regeneration stage of the adsorbent [1-3].

PSA processes are widely used in industry to extract hydrogen from gas mixtures, oxygenate the air, dehydrate gases, separate hydrocarbons, concentrate carbon dioxide, extract methane, and so on. One of the urgent problems in the field of adsorption separation is the production of hydrogen from hydrogen-containing process flows (gases of hydrocarbons conversion and oxidation, refinery gases, synthesis-gas, etc.). Typical substances that accompany hydrogen are nitrogen, carbon oxide and dioxide, methane. The adsorption production of hydrogen is noted for the fact that in 
mixtures of hydrogen-containing gases the accompanying components have a higher molecular mass than hydrogen and they are adsorbed more intensively than hydrogen [2].

Hydrogen is widely used in various industries due to its high chemical activity, exceptional lightness and a large amount of heat released during it combustion. It is mainly consumed by oil refining and petrochemical enterprises, where up to $50 \%$ of industrially produced hydrogen is used. In other industries, hydrogen is used both as the main raw material, as an auxiliary material and as fuel. According to statistics, total hydrogen consumption doubles every 15 years.

This work is aimed at: 1) developing a mathematical model of the process of adsorption separation of a gas mixture with a cyclically varying pressure and concentration of hydrogen in it; 2 ) studying the effect of changes in the temperature, composition and pressure of the initial gas mixture on the purity, recovery and production hydrogen at multiple duration periods of adsorption stage; 3 ) studying the dynamics of the adsorption process of the gas mixture components and the nature of the sorption and heat fronts motion along the height of the adsorbent bed in the adsorber, as well as the relationship between the output of the 4-column PSA unit and the purity of the hydrogen being produced.

\section{Technology of Adsorption Separation of a Gas Mixture and Hydrogen Production}

The technological process of hydrogen concentration by adsorption separation of gas mixture is implemented in a 4-column PSA unit (Fig. 1) [4]. The unit is designed for producing hydrogen with a concentration of $99.99 \%$ vol. from a gas mixture containing hydrogen $(65 \pm 2) \%$, carbon dioxide $(34 \pm 2) \%$ and carbon monoxide $(1 \pm 0.5) \%$ vol. The initial gas mixture is supplied to the unit after preliminary dehydration (the dehydration stage is not considered in this work) with an excess pressure of $2.1 \mathrm{MPa}$ and a temperature of $30^{\circ} \mathrm{C}$. The pressure rise in the adsorbers $\mathrm{A}_{1}-\mathrm{A}_{4}$ is provided by opening the controlled

valves $K_{1.1}, K_{2.1}, K_{3.1}$ and $K_{4.1}$, respectively, through which the gas is supplied to the adsorbent bed. The synthetic zeolite $\mathrm{CaA}$ is used as an adsorbent. The production hydrogen is removed from the adsorbers via the controlled valves $\mathrm{K}_{1.2}, \mathrm{~K}_{2.2}, \mathrm{~K}_{3.2}$ and $\mathrm{K}_{4.2}$ and is directed to the consumers through the receiver $\mathrm{P}$. Countercurrent regeneration of the adsorbent bed in the columns is carried out by passing the purge gas mixture through the valves $K_{12}, K_{13}, K_{14}, K_{23}, K_{24}$ and $K_{34}$. Through the valves $K_{1.3}, K_{2.3}, K_{3.3}$ and $K_{4.3}$ the purging gas is discharged at the regeneration stage.

The coordinated operation of the unit valves ensures the sequential passage by each adsorber of all the stages of the cyclic adsorption process, presented in Table 1.

The following designations in Table 1 have been adopted: $\mathrm{A}_{1}-\mathrm{A}_{4}$ - adsorbers; $\mathrm{AD}$ - adsorption; PE pressure equalizing (gas bypass); GD - gas discharge; $\mathrm{R}$ - regeneration; $\mathrm{PR}$ - pressure rise.

Granular active carbons and zeolites $\mathrm{CaA}$ and $\mathrm{NaX}$, having the largest capacity and selectivity for $\mathrm{CO}_{2}$ and $\mathrm{CO}$, are widely used as adsorbents in cyclic adsorption processes [1]. At present, the area

Table 1

Stages of the adsorption process of hydrogen production in a 4-column PSA unit

\begin{tabular}{|c|c|c|c|c|c|c|c|c|c|}
\hline $\mathrm{A}_{1}$ & \multicolumn{2}{|r|}{$\mathrm{AD}$} & PE 1 & PE 2 & GD & \begin{tabular}{l|l}
$\mathrm{R}$ & $\mathrm{PE}$ \\
\end{tabular} & PE 4 & \multicolumn{2}{|c|}{ PR } \\
\hline $\mathrm{A}_{2}$ & PE 4 & PR & \multicolumn{2}{|c|}{$\mathrm{AD}$} & PE 1 & PE 2 & GD & $\mathrm{R}$ & PE 3 \\
\hline $\mathrm{A}_{3}$ & GD & \begin{tabular}{l|l}
$\mathrm{R}$ & $\mathrm{PE} 3$
\end{tabular} & PE 4 & PR & \multicolumn{2}{|c|}{$\mathrm{AD}$} & PE 1 & \multicolumn{2}{|c|}{ PE 2} \\
\hline $\mathrm{A}_{4}$ & PE 1 & PE 2 & GD & \begin{tabular}{l|l}
$\mathrm{R}$ & $\mathrm{PE} 3$
\end{tabular} & PE 4 & PR & \multicolumn{3}{|c|}{$\mathrm{AD}$} \\
\hline
\end{tabular}


of obtaining composite sorption-active materials (CSAM) with prescribed properties is actively developing to be used in cyclic adsorption-desorption processes of hydrogen separation from synthesis-gas [5]. The most promising adsorbents to be used in PSA processes of hydrogen production are CSAM based on liquid and solid amines as well as organometallic compounds (metal hydroxides of $\mathrm{Fe}, \mathrm{Zr}, \mathrm{Co}, \mathrm{Ni}, \mathrm{Ti}$ ). They combine the advantages of zeolites and active coals because they do not adsorb moisture and at the same time can absorb harmful impurities. At present, technology has been developed for obtaining promising adsorbents for absorbing $\mathrm{CO}_{2}$ and $\mathrm{CO}$ when hydrogen is concentrated on the basis of a mesoporous organometallic framework structure in the form of granules with a diameter of $2 \mathrm{~mm}$ from hydrated zirconium dioxide stabilized with zinc salts. This type of adsorbent can purify gas mixtures from $\mathrm{CO}_{2}$ to concentrations of $\sim 5-10 \mathrm{ppm}$.

\section{Mathematical Description of Adsorption Processes with Cyclically Varying Pressure in Gas Mixtures Separation}

During adsorption of $\mathrm{H}_{2}, \mathrm{CO}_{2}$ and $\mathrm{CO}$ by a zeolite adsorbent, the following mass- and heat transfer processes proceed: a) diffusion of $\mathrm{H}_{2}, \mathrm{CO}_{2}$ and $\mathrm{CO}$ in a gas mixture flow; b) mass exchange of $\mathrm{H}_{2}, \mathrm{CO}_{2}, \mathrm{CO}$ and heat exchange between the gas phase and the adsorbent; c) adsorption of $\mathrm{H}_{2}, \mathrm{CO}_{2}, \mathrm{CO}$ on the surface and in micropores of zeolite adsorbent granules with heat release and desorption of $\mathrm{H}_{2}, \mathrm{CO}_{2}, \mathrm{CO}$ from micropores and from the surface of granules with heat absorption. Analysis of the results of physical modeling showed that diffusion of $\mathrm{H}_{2}, \mathrm{CO}_{2}, \mathrm{CO}$ and heat propagation in the gas flow and granular adsorbent are carried out mainly in the longitudinal direction relative to the flow of the gas mixture in the adsorber (along the height of the adsorbent). The process of hydrogen gas mixture enrichment during adsorption of $\mathrm{CO}_{2}$ and $\mathrm{CO}$ by the granular zeolite adsorbent is carried out in the mixed-diffusion region and is determined by the coefficients of external mass transfer and internal diffusion, as well as equilibrium ratios of the concentrations of $\mathrm{H}_{2}, \mathrm{CO}_{2}$ and $\mathrm{CO}$ in phases.

In the mathematical description of the process of hydrogen enrichment of gas mixture by $\mathrm{CO}_{2}$ and $\mathrm{CO}$ extracting from it in the PSA unit, the following assumptions were made: 1) the initial gas mixture is three-component (it contains 1 - production gas $\mathrm{H}_{2}$ with a concentration of ( $\left.65 \pm 2\right) \%$ vol.; 2 - dioxide carbon with a concentration of $(34 \pm 2) \%$ vol. and 3 - carbon oxide with a concentration of $(1 \pm 0.5) \%$ vol. and is treated as an ideal gas, which is quite acceptable at the adsorber pressure of 200 to $10^{5} \mathrm{~Pa}$ [6]; 2) granulated $\mathrm{CaA}$ zeolite with a granule diameter of $1.5 \mathrm{~mm}$, porosity granules coefficient $\sim 0.394$ and a diameter of transport pores $d_{\mathrm{e}} \leq 0,5 \times 10^{-3} \mathrm{~m}$ is used as an adsorbent; 3) the geometric dimensions of the adsorption layer are assumed to be constant for a preset lifetime of $\sim 10^{5} \mathrm{~h} \mathrm{[7];4)} \mathrm{the} \mathrm{adsorbent} \mathrm{layer} \mathrm{is}$ a continuous medium with a porosity factor $\varepsilon$, which takes into account the porosity of granules; 5) the desorption branch of the sorption isotherms of $\mathrm{H}_{2}, \mathrm{CO}_{2}$ and $\mathrm{CO}$ on the granular $\mathrm{CaA}$ zeolite coincides with the adsorption branch [3];6) the adsorption equilibrium is described by the Langmuir-Freundlich equation [8].

In accordance with the accepted assumptions, the mathematical description of the process of $\mathrm{CO}_{2}, \mathrm{CO}$ extracting from the gas mixture by PSA method and concentrating $\mathrm{H}_{2}$ in the gas mixture flow includes the following equations.

1. The equation of the componentwise material balance $k=\left\{1-\mathrm{H}_{2}, 2-\mathrm{CO}_{2}, 3-\mathrm{CO}\right\}$ in the gas mixture flow along the height of the adsorbent bed

$$
\begin{gathered}
\frac{\partial c_{k}(x, t)}{\partial t}+\frac{(1-\varepsilon)}{\varepsilon} \frac{\partial a_{k}}{\partial t}+\frac{\partial\left(v_{\mathrm{g}} c_{k}(x, t)\right)}{\partial x}= \\
=\frac{\partial}{\partial x}\left(D_{\mathrm{g}}^{k}(x) \frac{\partial}{\partial x} c_{k}(x, t)\right),
\end{gathered}
$$

where $v_{\mathrm{g}}$ is the gas flow rate $(\mathrm{m} / \mathrm{s}) ; c_{k}$ is molar concentration of the $k$-th component of the gas mixture $\left(\mathrm{mol} / \mathrm{m}^{3}\right) ; a_{k}$ is the amount of sorption of the $k$-th component in the adsorbent $\left(\mathrm{mol} / \mathrm{m}^{3}\right) ; \varepsilon$ is the porosity of the adsorbent taking into account the porosity of granules, $\left(\mathrm{m}^{3} / \mathrm{m}^{3}\right) ; D_{\mathrm{g}}^{k}$ is effective coefficient of longitudinal mixing of the $k$-th component in the gas mixture $\left(\mathrm{m}^{2} / \mathrm{s}\right) ; x$ is a spatial coordinate of adsorbent bed (height in the adsorber) (m); $t$ is the time (s).

In equation (1), the first term describes the rate of accumulation of the $k$-th component of the mixture in the gas phase; the second term is the rate of accumulation of the $k$-th component in the adsorbent; the third term is the convective transfer of substance in the adsorbent bed; the fourth term is the longitudinal mixing of the $k$-th component in the adsorbent bed.

2. The equation of mass transfer of the adsorbate $\left(\mathrm{H}_{2}, \mathrm{CO}_{2}, \mathrm{CO}\right)$ from the gas phase to the solid phase of the adsorbent (through the interface):

$$
\begin{gathered}
\frac{\partial a_{k}}{\partial t}=\frac{F_{k}^{2}-F_{k}^{1}}{2} \operatorname{tgh}\left(\theta\left(v_{\mathrm{g}}-v_{\mathrm{g}}^{*}\right)+1\right)+F_{k}^{1} ; \\
k=\mathrm{H}_{2}, \mathrm{CO}_{2}, \mathrm{CO},
\end{gathered}
$$

where $F_{k}^{1}$ is the right-hand side of the equation of the kinetics of non-stationary convective (external) mass transfer, $F_{k}^{1}=\beta_{k}^{1}\left(c_{k}-c_{k}^{*}\right) ; \beta_{k}^{1}$ is coefficient of mass 
transfer, referred to the concentration of adsorbate in the gas phase; $c_{k}^{*}$ is equilibrium concentration in a gas phase; $F_{k}^{2}$ is right-hand side of the equation of the kinetics of the intradiffusion adsorption process, $F_{k}^{2}=\beta_{k}^{2}\left(a_{k}^{*}-a_{k}\right) ; \beta_{k}^{2}$ is the kinetic coefficient; $a_{k}^{*}$ is adsorption amount or equilibrium concentration in a solid phase; $v_{g}^{*}$ is the critical rate of the gas mixture, which determines the transition from the diffusion region (external mass transfer) to the kinetic region (internal diffusion in the adsorbent granules) of the adsorbate transfer $\left(\mathrm{H}_{2}, \mathrm{CO}_{2}, \mathrm{CO}\right)$.

Equation (2) is a description of the adsorption kinetics for the mixed-diffusion transport region of adsorbate $\left(\mathrm{H}_{2}, \mathrm{CO}_{2}, \mathrm{CO}\right)$ across the interface (Fig. 2): at a gas mixture velocity below $v_{g}^{*}$, the adsorption process is limited by the external masstransfer process with coefficient $\beta_{k}^{1}$, otherwise - by the process of internal diffusion in adsorbent granules with kinetic coefficient $\beta_{k}^{2}$. The hyperbolic tangent and formal coefficient $\theta$ allow smoothly adjusting the dimensions of the mixed-diffusion region of the adsorption process $\mathrm{CO}_{2}$ and $\mathrm{CO}$ by the adsorbent.

The mass-transfer coefficient $\beta_{k}^{1}$, formal kinetic coefficients $\beta_{k}^{2}$ and $\theta$ were corrected from experimental data by solving the inverse coefficient problem using the equations of the mathematical model: $v_{\mathrm{g}}^{*}=0.022 \mathrm{M} / \mathrm{s} ; \beta_{\mathrm{H}_{2}}^{1}=0.816 \mathrm{~s}^{-1} ; \beta_{\mathrm{CO}_{2}}^{1}=0.021 \mathrm{~s}^{-1}$; $\beta_{\mathrm{CO}}^{1}=0.084 \mathrm{~s}^{-1} ; \quad \beta_{\mathrm{H}_{2}}^{2}=0.73 \mathrm{~s}^{-1} ; \quad \beta_{\mathrm{CO}_{2}}^{2}=0.012 \mathrm{~s}^{-1}$; $\beta_{\mathrm{CO}}^{2}=0.059 \mathrm{~s}^{-1} ; \theta=18.2$. The adsorption amount $a_{k}^{*}$, or equilibrium concentration of adsorbate $c_{k}$ in the flow on the outer surface of the granules, is calculated by the Langmuir-Freindlich formula

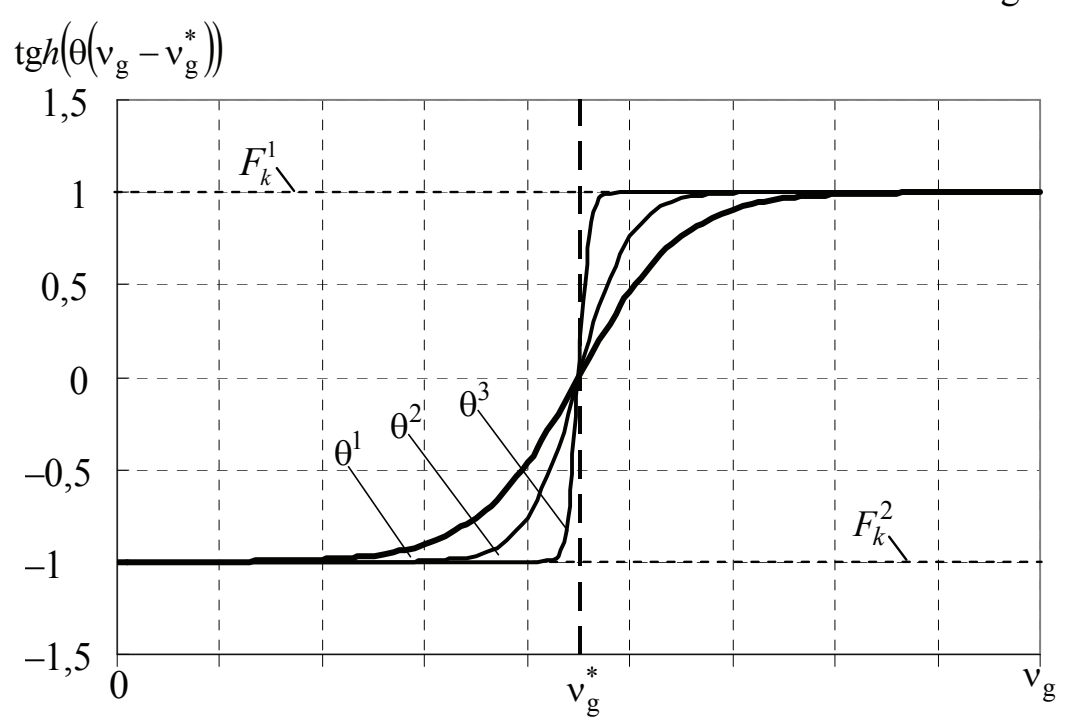

Fig. 2. The effect of $\theta$ on the sizes of the mixed-diffusion region

$$
a_{k}^{*}=\frac{\left(b_{1, k}-b_{2, k} T_{a}\right) b_{3, k} \mathrm{e}^{b_{4, k} / T_{a}} c_{k}{ }^{\left(b_{5, k}+b_{6, k} / T_{a}\right)}}{1+\sum_{j} b_{3, j} \mathrm{e}^{b_{4, j} / T_{a}} c_{j}{ }^{\left(b_{5, j}+b_{6, j} / T_{a}\right)}},
$$

where $b$ is the parameter vector of the sorption isotherm [8]; $T_{a}$ is the adsorbent temperature.

3. The equation describing the propagation of heat in the gas mixture flow along the height of the adsorbent:

$$
\begin{aligned}
c_{p}^{\mathrm{g}} \rho_{\mathrm{g}} \frac{\partial T_{\mathrm{g}}(x, t)}{\partial t} & +c_{p}^{\mathrm{g}} \rho_{\mathrm{g}} v_{\mathrm{g}} \frac{\partial T_{\mathrm{g}}(x, t)}{\partial x}-\frac{\alpha}{\varepsilon} S_{u}\left[T_{a}(x, t)-T_{\mathrm{g}}(x, t)\right]= \\
& =\lambda_{\mathrm{g}} \frac{\partial^{2} T_{\mathrm{g}}}{\partial x^{2}}, 0<x<L
\end{aligned}
$$

where $c_{p}^{\mathrm{g}}, \rho_{\mathrm{g}}$ is the specific heat and molar density of the gas mixture, respectively, $\mathrm{J} /(\mathrm{mol} \cdot \mathrm{K}), \mathrm{mol} / \mathrm{m}^{3}$; $v_{\mathrm{g}}$ is velocity of the gas mixture, $\mathrm{m} / \mathrm{s} ; T_{\mathrm{g}}$ is temperature of the gas mixture, $\mathrm{K} ; T_{a}$ is the adsorbent temperature, $\mathrm{K} ; \lambda_{\mathrm{g}}$ is coefficient of thermal conductivity of the gas mixture, $\mathrm{W} /(\mathrm{m} \cdot \mathrm{K}) ; \alpha$ is the coefficient of heat transfer from the surface of the adsorbent granules to the gas mixture flow, $\mathrm{W} /\left(\mathrm{K} \cdot \mathrm{m}^{2}\right)$; $S_{u}=(1-\varepsilon) \frac{3}{r_{\mathrm{gr}}}$ is the specific surface area coefficient of the adsorbent granules, $\mathrm{m}^{2} / \mathrm{m}^{3} ; r_{\mathrm{gr}}$ is the radius of the adsorbent granule, $\mathrm{m}$.

In equation (3), the first term describes the accumulation of heat in the gas phase; the second term describes the convective component of heat transfer; the third term - the heat transfer from the gas phase to the solid phase (adsorbent); the fourth term - the longitudinal thermal conductivity of the gas phase along the height of the adsorbent bed.

4. The equation describing the temperature change in the adsorbent

$$
\begin{gathered}
c_{p}^{a} \rho_{a} \frac{\partial T_{a}(x, t)}{\partial t}+\alpha S_{u}\left[T_{a}(x, t)-T_{\mathrm{g}}(x, t)\right]- \\
-\sum_{k} h_{k}^{a} \frac{\partial a_{k}(x, t)}{\partial t}=\lambda_{a} \frac{\partial^{2} T_{a}(x, t)}{\partial x^{2}},
\end{gathered}
$$

where $c_{p}^{a}$ is the specific heat capacity of the adsorbent, $\mathrm{J} /(\mathrm{kg} \cdot \mathrm{K}) ; \rho_{a}$ is the adsorbent density, $\mathrm{kg} / \mathrm{m}^{3} ; c_{p}^{\mathrm{g}}$ is the specific heat of adsorbate, $\mathrm{J} /(\mathrm{mol} \cdot \mathrm{K})$; $h_{k}^{a}$ is heat of adsorption of the $k$-th component of the gas mixture, $\mathrm{J} / \mathrm{mol}$; $\lambda_{a}$ is coefficient of thermal conductivity of the adsorbent, $\mathrm{W} /(\mathrm{m} \cdot \mathrm{K})$. 
In equation (4), the first term describes the enthalpy of the solid phase (adsorbent); the second term describes the heat transfer from the solid phase (adsorbent) to the gas phase; the third term - the heat release of the gas mixture components sorption; the fourth term - the thermal conductivity in the adsorbent along the vertical axis of the adsorber.

5. The Ergun equation describing the change in pressure and velocity of the gas mixture along the height of the adsorbent [9]

$$
\frac{\partial P}{\partial x}=-\left(\frac{150\left(1-\varepsilon_{0}\right)^{2}}{\left(2 r_{\mathrm{gr}} \psi\right)^{2} \varepsilon_{0}^{2}} \mu_{\mathrm{g}} \nu_{\mathrm{g}}+1,75 M_{\mathrm{g}} \rho_{\mathrm{g}} \frac{\left(1-\varepsilon_{0}\right)}{2 r_{\mathrm{gr}} \psi \varepsilon_{0}} \nu_{\mathrm{g}}^{2}\right) \text {, }
$$

where $\varepsilon_{0}$ is the porosity of the adsorbent bed without taking into account the porosity of the particles, $\mathrm{m}^{3} / \mathrm{m}^{3}$; $\psi$ is the sphericity factor of the adsorbent granules; $\mu_{\mathrm{g}}$ is the dynamic viscosity of the gas mixture, $(\mathrm{H} \cdot \mathrm{s}) / \mathrm{m}^{2} ; M_{\mathrm{g}}$ is Molar mass of the gas mixture, $\mathrm{kg} / \mathrm{mol}$.
The initial and boundary conditions for equations (1) - (5) are given in Table 2.

In formulas (7), $\left(8^{\prime}\right) S$ is the cross-sectional area of the adsorber, $\mathrm{m}^{2}$.

Formulas for calculating the coefficients of the mathematical model are presented in Table 3.

The effective coefficients of longitudinal mixing of the components of the gas mixture $D_{\mathrm{g}}^{k}$ were calculated by formulas (9) - (11) [10], where: $D_{\mathrm{gm}}^{k}$ are the molecular diffusion coefficients of the corresponding component, $\mathrm{m}^{2} / \mathrm{s} ; D_{12}, D_{13}, D_{23}$ are molecular diffusion coefficients calculated for a two-component gas mixture, $\mathrm{m}^{2} / \mathrm{s} ; M_{\mathrm{g} 1}, M_{\mathrm{g} 2}, M_{\mathrm{g} 3}$ are molar masses $\mathrm{H}_{2}, \mathrm{CO}_{2}, \mathrm{CO}$, respectively, mol $/ \mathrm{m}^{3} ; \vartheta_{1}, \vartheta_{2}, \vartheta_{3}$ are diffusion volumes $\mathrm{H}_{2}, \mathrm{CO}_{2}, \mathrm{CO}$, respectively, $\mathrm{m}^{3} / \mathrm{mol}$. The initial approximations for the masstransfer coefficient $\beta_{k}^{(0)}$ and the formal kinetic

Table 2

The initial and boundary conditions for equations (1) - (5)

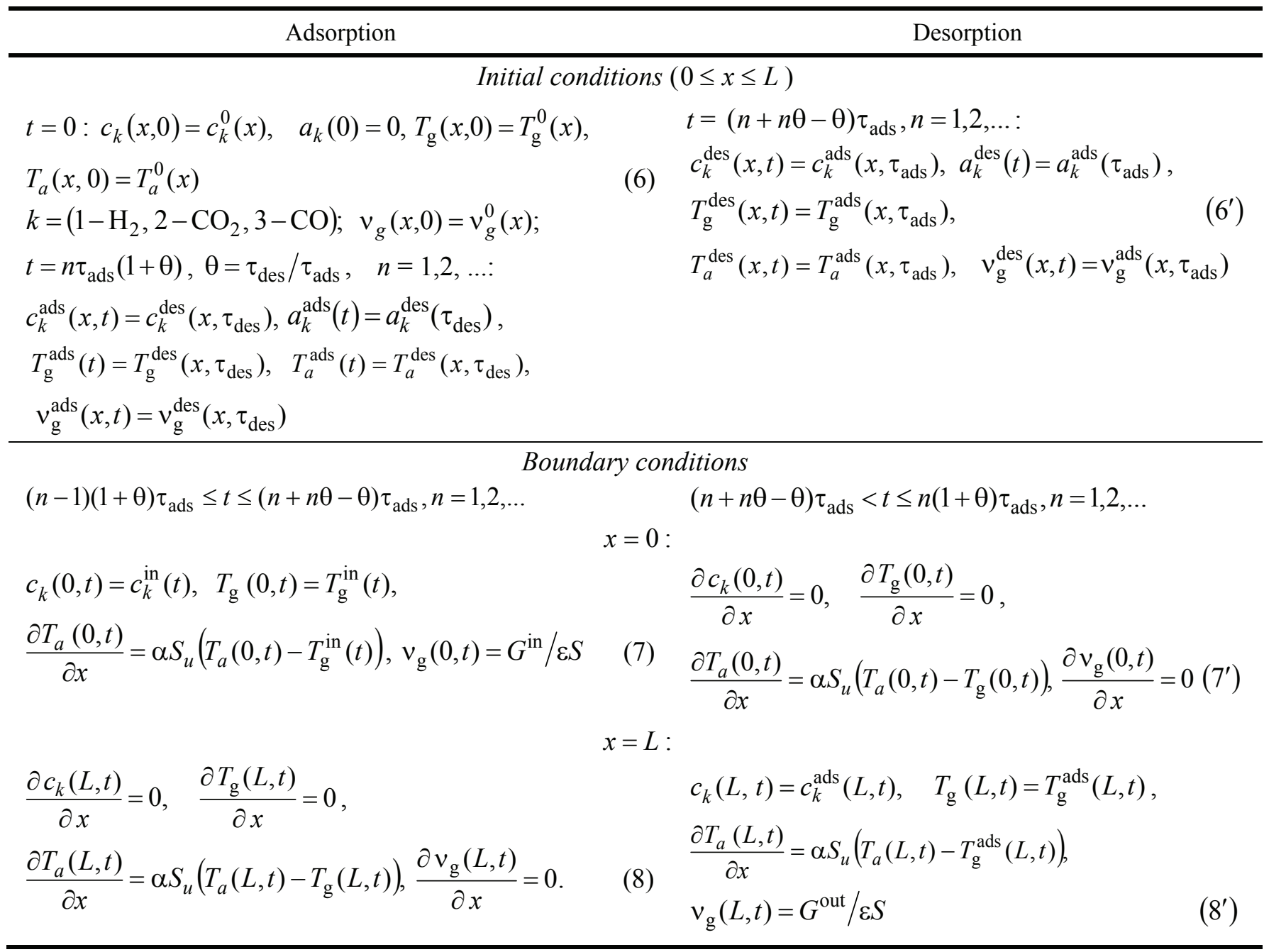


Table 3

Formulas for calculating the coefficients of the model (1) - (8)

$$
\begin{aligned}
& D_{\mathrm{g}}^{k}=0,7 D_{\mathrm{gm}}^{k}+r_{\mathrm{gr}} v_{\mathrm{g}} \\
& D_{\mathrm{gm}}^{1}=\left(c_{2}+c_{3}\right) \frac{1}{\frac{c_{2}}{D_{12}}+\frac{c_{3}}{D_{13}}} ; D_{\mathrm{gm}}^{2}=\left(c_{1}+c_{3}\right) \frac{1}{\frac{c_{1}}{D_{12}}+\frac{c_{3}}{D_{23}}} ; D_{\mathrm{gm}}^{3}=\left(c_{1}+c_{2}\right) \frac{1}{\frac{c_{1}}{D_{13}}+\frac{c_{2}}{D_{23}}} ; \\
& D_{12}=\frac{10^{-7} T_{\mathrm{g}}^{1,75}\left[\frac{\left(M_{\mathrm{g} 1}+M_{\mathrm{g} 2}\right)}{M_{\mathrm{g} 1} M_{\mathrm{g} 2}}\right]^{\frac{1}{2}}}{P\left(\vartheta_{1^{\frac{1}{3}}}+\vartheta_{2} \frac{1}{3}\right)^{2}} ; D_{23}=\frac{10^{-7} T_{\mathrm{g}}^{1,75}\left[\frac{\left(M_{\mathrm{g} 2}+M_{\mathrm{g} 3}\right)}{M_{\mathrm{g} 2} M_{\mathrm{g} 3}}\right]^{\frac{1}{2}}}{P\left(\vartheta_{2}^{\frac{1}{3}}+\vartheta_{3}^{\frac{1}{3}}\right)^{2}} ; \\
& D_{13}=\frac{10^{-7} T_{\mathrm{g}}^{1,75}\left[\frac{\left(M_{\mathrm{g} 1}+M_{\mathrm{g} 3}\right)}{M_{\mathrm{g} 1} M_{\mathrm{g} 3}}\right]^{\frac{1}{2}}}{P\left(\vartheta_{\mathrm{g} 1}^{\frac{1}{3}}+\vartheta_{\mathrm{g} 3} \frac{1}{3}\right)^{2}} \\
& \beta_{K}^{1(0)}=A \operatorname{Re}^{m} S c^{n} \frac{D_{H_{K}}}{4 r_{\mathrm{gr}}^{2}} 4 ; \quad \operatorname{Re}=\frac{4}{3} \frac{\omega \varepsilon \rho_{\mathrm{g}} \nu_{\mathrm{gr}}}{\mu_{\mathrm{g}}(1-\varepsilon)} ; \quad S c=\frac{\mu_{\mathrm{g}}}{\rho_{\mathrm{g}} D_{H_{K}}} ; \\
& \beta_{K}^{2(0)}=15 \frac{D_{H_{K}} \varepsilon}{r_{\mathrm{gr}}^{2} K^{2}} ; \\
& \alpha_{\mathrm{g}}=\frac{0,12 \mathrm{Re}^{0,83} \lambda_{\mathrm{g}}}{r_{\mathrm{gr}}} \\
& \lambda_{\mathrm{g}}=\frac{1}{2}\left(\lambda_{1} c_{1}+\lambda_{2} c_{2}+\lambda_{3} c_{3}+\frac{1}{\frac{c_{1}}{\lambda_{1}}+\frac{c_{2}}{\lambda_{2}}+\frac{c_{3}}{\lambda_{3}}}\right) \quad \lambda_{k}=\lambda_{k, 0}+\Delta \lambda_{k, 1}\left(T_{\mathrm{g}}-273,15\right), \quad k=1,2,3 ; \\
& P=\rho_{\mathrm{g}} R T_{\mathrm{g}}, \rho_{\mathrm{g}}=\sum_{k=1}^{k=3} c_{k} \\
& a_{k}^{*}=\frac{\left(b_{1, k}-b_{2, k} T_{a}\right) b_{3, k} e^{b_{4, k} / T_{a}} c_{k}\left(b_{5, k}+b_{6, k} / T_{a}\right)}{1+\sum_{n=1}^{3} b_{3, n} e^{b_{4, n} / T_{a}} c_{n}{ }^{\left(b_{5, n}+b_{6, n} / T_{a}\right)}}, k=1,2,3 \text {; } \\
& \left\{a_{k}=\frac{\left(b_{1, k}-b_{2, k} T_{\mathrm{a}}\right) b_{3, k} \mathrm{e}^{b_{4, k} / T_{a}} c_{k}^{\left.* b_{5, k}+b_{6, k} / T_{a}\right)}}{1+\sum_{n=1}^{3} b_{3, n} \mathrm{e}^{b_{4, n} / T_{a}} c_{n}^{*\left(b_{5, n}+b_{6, n} / T_{a}\right)}}, k=1,2,3\right. \\
& c_{v}^{g}=10^{-3}\left(T_{\mathrm{g}}-273,15\right) \sum_{k=1}^{n_{k}} c_{k}\left(A_{k}+B_{k} T_{\mathrm{g}}+C_{k} T_{\mathrm{g}}^{2}+D_{k} T_{\mathrm{g}}^{3}\right) \\
& \mu_{\mathrm{g}}=\frac{\mu_{1} c_{1}}{\sum_{j=1}^{3} c_{1} \sqrt{\frac{M_{1}}{M_{j}}}}+\frac{\mu_{2} c_{2}}{\sum_{j=1}^{3} c_{2} \sqrt{\frac{M_{2}}{M_{j}}}}+\frac{\mu_{3} c_{3}}{\sum_{j=1}^{3} c_{3} \sqrt{\frac{M_{3}}{M_{j}}}} .
\end{aligned}
$$


coefficient $\beta_{k}^{2^{(0)}}$ were calculated using formulas (12), (13) [10], where $D_{H_{K}}$ are the normal diffusion coefficients $\mathrm{H}_{2}, \mathrm{CO}_{2}, \mathrm{CO} ; \mathrm{A}, \mathrm{m}, \mathrm{n}$ are approximation coefficients, $d_{q}$ is the equivalent diameter of the channels between the granules $d_{q}=\frac{4 \varepsilon r_{\mathrm{gr}}}{3(1-\varepsilon)}, \mathrm{m}$; $\mathrm{K}$ is the tortuosity coefficient of the pore channels in the adsorbent [12]. The initial approximation $\theta$ was assumed to be equal to 1 . The heat transfer coefficient $\alpha$ from the surface of the adsorbent granules to the gas mixture flow was calculated using formula (14) where: $\lambda_{g}$ is the thermal conductivity coefficient of the gas mixture calculated by formula (15), where values $\lambda_{k, 0}$, $\lambda_{k, 1}$ for the corresponding component and the thermal conductivity coefficient of the adsorbent $\lambda_{a}$ for zeolite $\mathrm{CaA}$ are calculated according to [3]. The current pressure values in the Ergun equation (5) were calculated through the concentrations of the components in the gas phase using formula (16). In calculating the equilibrium values of the concentrations of the components in the solid phase $a_{k}^{*}$, using formula (17), the parameters $b_{1-6, k}$ of adsorption isotherms $\mathrm{H}_{2}, \mathrm{CO}_{2}, \mathrm{CO}$ on CaA zeolite were used [8]. The values of the equilibrium concentrations of the components in the gas phase $c_{k}^{*}$ were determined from the solution of the system of equations (18). Formula (19) for calculating the specific heat capacity of the gas mixture $c_{v}^{\mathrm{g}}$ and the approximating polynomial coefficients $A_{k}, B_{k}$, $C_{k}, D_{k}$ for gases $\mathrm{H}_{2}, \mathrm{CO}_{2}, \mathrm{CO}$ were borrowed from the literature [10]. The coefficient of dynamic viscosity of the gas mixture $\mu_{\mathrm{g}}$ was calculated by the HerningZipperer method [10].

The volumetric flow rate directed to the receiver $P$ (Fig. 1) was determined as $G^{P}=G^{\text {out }}-G^{a}$, where $G^{a}=\chi G^{\text {in }} \frac{P^{d}}{P^{a}}$ is part of the input flow directed to $\mathrm{CO}_{2}$ and $\mathrm{CO}$ desorption and discharge into the atmosphere, $\chi$ is the reflux ratio [1].

Thus, equations (1) - (20) reperesent a mathematical description of cyclic adsorption-desorption processes carried out in adsorbers $\mathrm{A}_{1}-\mathrm{A}_{4}$ (see Fig. 1).

The mathematical description of the adsorptiondesorption processes taking place in the adsorber includes a system of differential and algebraic equations. To solve a system of partial differential equations, we will use the method of lines. Let us replace the spatial coordinate derivatives $x$ by finitedifference formulas and seek the solution of the boundary-value problem (the system of differential equations in ordinary derivatives) by the fourth-order Runge-Kutta method along some family of lines.

The algorithm for solving equations (1) - (5) with the initial and boundary conditions (6) - (8) and design formulas for coefficients (9) - (20) is given in [13].

The mismatch of the design values in each cycle at the adsorption stage is estimated on the basis of the material balance on hydrogen

$$
\begin{gathered}
E=\int_{0}^{\tau_{\mathrm{a}}}\left(v_{\mathrm{g}}(0, t) c_{1}(0, t)-v_{\mathrm{g}}(L, t) c_{1}(L, t)\right) d t- \\
-\int_{0}^{L}\left(c_{1}\left(x, \tau_{a}\right)-c_{1}(x, 0)+\rho_{\mathrm{a}}\left(\frac{1-\varepsilon_{0}}{\varepsilon_{0}}\right)\left(a_{1}\left(x, \tau_{a}\right)-a_{1}(x, 0)\right)\right) d x .
\end{gathered}
$$

The adequacy of the mathematical model was checked by the results of independent experiments, i.e. different from the experimental data used to identify the model.

Further, the concentrations of hydrogen, carbon dioxide and monoxide will be denoted by $y=\left(y_{1}, y_{2}, y_{3}\right) \%$ vol.

The results of the solution of the problem of parametric identification of the mathematical model of the adsorption hydrogen production in a 4-column PSA unit are shown in Fig. 3.

To evaluate the accuracy of the model, we used a function in the form

$$
\delta(t)=\left(\left|y_{1}^{\text {out }, e}(t)-y_{1}^{\text {out }}(t)\right| / y_{1}^{\text {out }, e}(t)\right) 100 \% .
$$

The maximum relative error $\delta(t)$ of the mismatching between the values calculated by the model $y_{1}^{\text {out }}$ and the experimental data $y_{1}^{\text {out } e}$ at the adsorption stage does not exceed $11.4 \%$, which makes it possible to use the model for the purposes of technological calculation, optimization and control of the process of hydrogen production by the method of adsorption separation of a gas mixture with an accuracy acceptable in practice.

The mathematical description of the operation mode of the valves is described by the cyclogram $\mathbf{u}=\mathbf{u}(\tau)$ (not shown in the the Figure) according to Table 1, where $\mathbf{u}$ is a vector-function whose components are Boolean variables taking the values 0 or 1. Gas flow rates through the shut-off valves K1.1 - K4.1; К1.2 - К4.2; К1.3 - K4.3; К12; К13; $\mathrm{K} 14 ; \mathrm{K} 23 ; \mathrm{K} 24 ; \mathrm{K} 34$ are determined from the solution of the following system:

$$
\begin{aligned}
& G_{1.1}=k_{V} \Delta P_{1.1} u_{1.1} ; G_{2.1}=k_{V} \Delta P_{2.1} u_{2.1} ; \\
& G_{3.1}=k_{V} \Delta P_{3.1} u_{3.1} ; G_{4.1}=k_{V} \Delta P_{4.1} u_{4.1} ;
\end{aligned}
$$




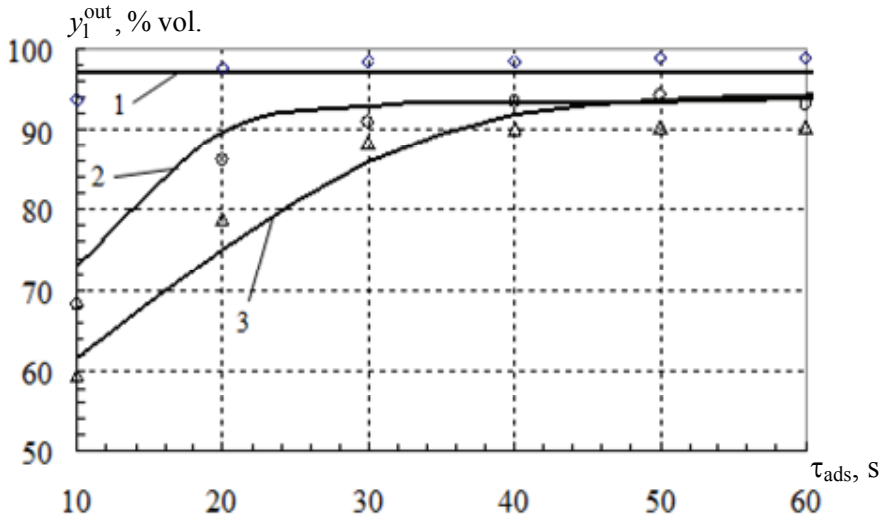

a)

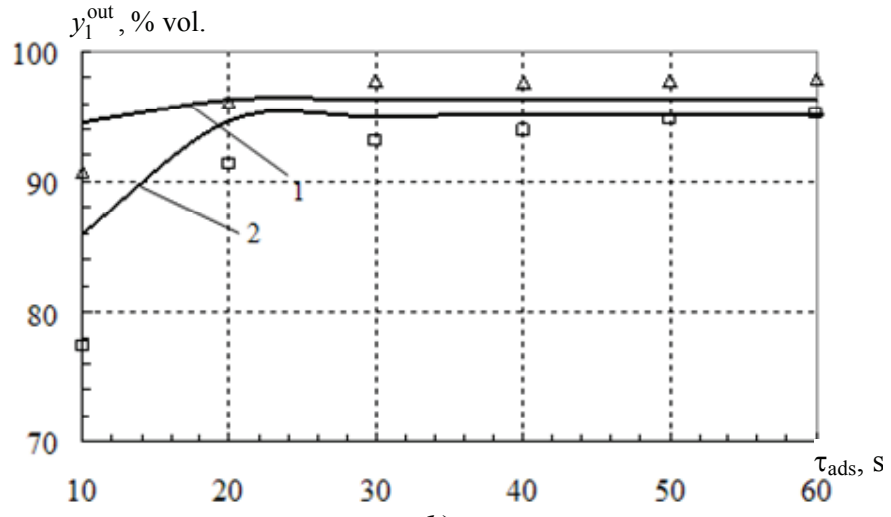

b)

Fig. 3. Dynamics of the changes in the hydrogen concentration $y_{1}^{\text {out }}, \%$ vol. at the output of the PSA unit at the $\mathrm{CO}_{2}$ concentration in the initial mixture $1-10 \%$ vol.; $2-40 \%$ vol.; $3-50 \%$ vol. (a); $1-20 \%$ vol.; $2-30 \%$ vol. $(b)$ : $\diamond, \circ, \Delta$ - experiment, solid line - calculation by the model

$$
\begin{aligned}
& G_{1.2}=k_{V} \Delta P_{1.2} u_{1.2} ; G_{2.2}=k_{V} \Delta P_{2.2} u_{2.2} ; \\
& G_{3.2}=k_{V} \Delta P_{3.2} u_{3.2} ; G_{4.2}=k_{V} \Delta P_{4.2} u_{4.2} ; \\
& G_{1.3}=k_{V} \Delta P_{1.3} u_{1.3} ; G_{2.3}=k_{V} \Delta P_{2.3} u_{2.3} ; \\
& G_{3.3}=k_{V} \Delta P_{3.3} u_{3.3} ; G_{4.3}=k_{V} \Delta P_{4.3} u_{4.3} ; \\
& G_{12}=k_{V} \Delta P_{12} u_{12} ; G_{13}=k_{V} \Delta P_{13} u 13 ; \\
& G_{14}=k_{V} \Delta P_{14} u_{14} ; \\
& G_{23}=k_{V} \Delta P_{23} u_{23} ; G_{24}=k_{V} \Delta P_{24} u_{24} ; \\
& G_{34}=k_{V} \Delta P_{34} u_{34} .
\end{aligned}
$$

where $k_{V}$ is the capacity of valves $\mathrm{K} 1.1-\mathrm{K} 4.1$, K1.2 - К4.2, К1.3 - К4.3, К12, К13, К14, К23, К24, $\mathrm{K} 34 ; \Delta P$ is a pressure drop on the specified valves; $u_{i j}$ is components of vector $\mathbf{u}$, which determine the state variables of the valves.

The flow through the control valve $K_{5}$ is calculated by the formula

$$
G_{5}=k_{V}^{5} \psi_{5} \Delta P,
$$

where $k_{V}^{5}$ is the capacity of valve $\mathrm{K} 5 ; \psi_{5}$ is valve opening degree $\mathrm{K}_{5} ; \Delta P$ is pressure drop on valve $\mathrm{K}_{5}$.

The mathematical description of the receiver includes the equations of dynamics ofpressure and concentrations of gas mixture components.

The equation of pressure dynamics in the receiver is described by the equation

$$
V_{m} \frac{V_{\text {res }}}{R T_{\mathrm{g}}} \frac{d P_{\text {res }}}{d t}=G^{*}-G_{p},
$$

with initial condition $P_{\text {res }}(0)=P^{*}$; where $V_{m}$ is molar volume, $\mathrm{m}^{3} / \mathrm{mol}$; $V_{\text {res }}$ is volume of the receiver, $\mathrm{m}^{3}$;
$P_{\text {res }}$ is gas mixture pressure in the receiver, $\mathrm{Pa}$; $G_{p}$ is flow rate of the consumed production gas mixture, $\mathrm{m}^{3} / \mathrm{s}, G^{*}$ is flow rate of the production gas mixture from adsorbers $A_{1}-A_{4}, \mathrm{~m}^{3} / \mathrm{s}$ is defined by the following logical expression

$$
G^{*}=G_{1.2} u_{1.2} \vee G_{2.2} u_{2.2} \vee G_{3.2} u_{3.2} \vee G_{4.2} u_{4.2} .
$$

The equation of the dynamics of the changes in the components concentrations $\left(1-\mathrm{H}_{2} ; 2-\mathrm{CO}_{2}\right.$; $3-\mathrm{CO}$ ) of the gas mixture in the receiver is described by the equation

$$
\frac{d c_{k, \text { res }}^{\text {out }}}{d t}=\frac{1}{V_{\text {res }}}\left(G^{*} c_{k, \text { res }}^{\text {in }}-G_{p} c_{k, \text { res }}^{\text {out }}\right), k=1,2,3,
$$

with initial condition $c_{k, \text { res }}^{\text {out }}(0)=c_{k, \text { res }}^{\text {out } 0}$.

\section{Numerical Investigation of Gas Mixture Enrichment with Hydrogen}

Analysis of the PSA process of gas mixture enrichment with hydrogen as an object of research made it possible to determine [13, 14] (Fig. 4): input

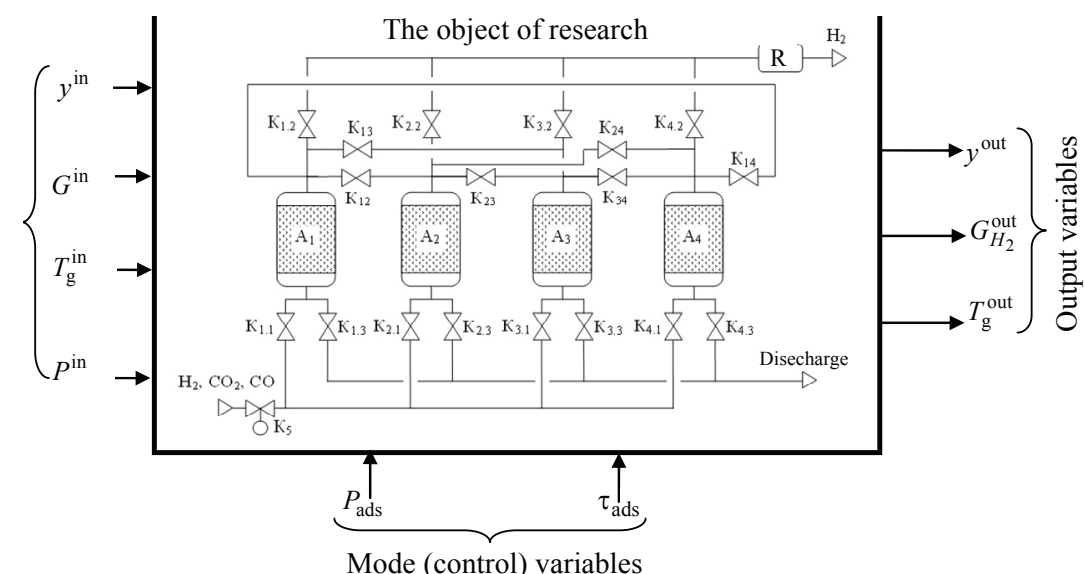

Fig. 4. Scheme of the 4-column PSA unit as an object of investigation in the production of hydrogen:

$\mathrm{A}_{1}-\mathrm{A}_{4}$ - adsorbers; $\mathrm{K}$ - controlled valves; $\mathrm{R}$ - receiver 
variables (composition $\quad y^{\text {in }}=\left(y_{1}^{\text {in }}, y_{2}^{\text {in }}, y_{3}^{\text {in }}\right)$, temperature $T_{\mathrm{g}}^{\text {in }}$ and pressure $P^{\text {in }}$ of the initial gas mixture); mode (control) variables (pressure $P_{\text {ads }}$ and cycle duration $\tau_{\mathrm{ads}}$ of the adsorption stage); output variables (composition $y^{\text {out }}=\left(y_{1}^{\text {out }}, y_{2}^{\text {out }}, y_{3}^{\text {out }}\right)$, flow rate $G^{\text {out }}$ and temperature $T_{\mathrm{g}}^{\text {out }}$ of the gas mixture at the output of the PSA unit, unit output $G_{H_{2}}^{\text {out }}=y_{1}^{\text {out }} G^{\text {out }}$ ).

Computational experiments were performed to numerically study the effect of input variables and control actions on the output variables of the process of adsorption separation of a gas mixture and hydrogen production. Varying variables and size of their changes are presented in Table 4.

Figure 5 shows the design graphs of pressure changes in adsorbers $\mathrm{A}_{1}-\mathrm{A}_{4}$ depending on time. The dynamics of the pressure changes in the adsorbers fully corresponds to the cyclogram (Table 1) of the pressure change in the 4-column unit for hydrogen production.

Consider the operation of the unit using adsorber $\mathrm{A}_{1}$ as an example. The initial rectilinear section in Fig. 5 (segment 1-2) corresponds to the adsorption stage. We note that all the sections with constant pressure correspond to the course of the adsorption process.

At the time moment corresponding to point 2, the adsorption process in adsorber $A_{1}$ is completed and the gas, filling it, is discharged into adsorber $A_{3}$, at the same time the pressure in $\mathrm{A}_{1}$ decreases, while the pressure in $\mathrm{A}_{3}$ increases (segment 2-3). At point 3, the remaining gas from adsorber $A_{1}$ is fed to the counterflow purge of adsorber $\mathrm{A}_{4}$, in so doing, the pressure in $A_{1}$ continues to fall (section 3-4). When the adsorbent in the adsorber $\mathrm{A}_{4}$ is completely restored (point 4 ), the pressure in $\mathrm{A}_{4}$ slightly increases, while the pressure in $A_{1}$ it continues to fall (segment 4-5).

Table 4

\section{Initial data for a computational experiment}

\begin{tabular}{|c|c|}
\hline Parameter name & $\begin{array}{c}\text { Size of } \\
\text { changes }\end{array}$ \\
\hline Adsorption stage duration, $\tau_{\mathrm{ads}}, \mathrm{s}$ & $25-200$ \\
\hline $\begin{array}{l}\text { The ratio of desorption stage duration to } \\
\text { adsorption stage duration, } \gamma=\tau_{\mathrm{des}} / \tau_{\mathrm{ads}} \text {, } \\
\text { rel.units }\end{array}$ & $0,2-0,8$ \\
\hline 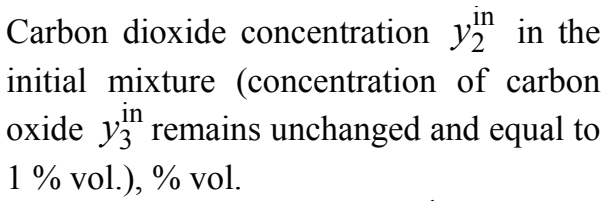 & $25-45$ \\
\hline Initial mixture temperature, $T_{\mathrm{g}}^{\mathrm{in}},{ }^{\circ} \mathrm{C}$ & $10-50$ \\
\hline Initial gas mixture pressure, $P^{\text {in }}, \mathrm{MPa}$ & $0,5-3$ \\
\hline
\end{tabular}

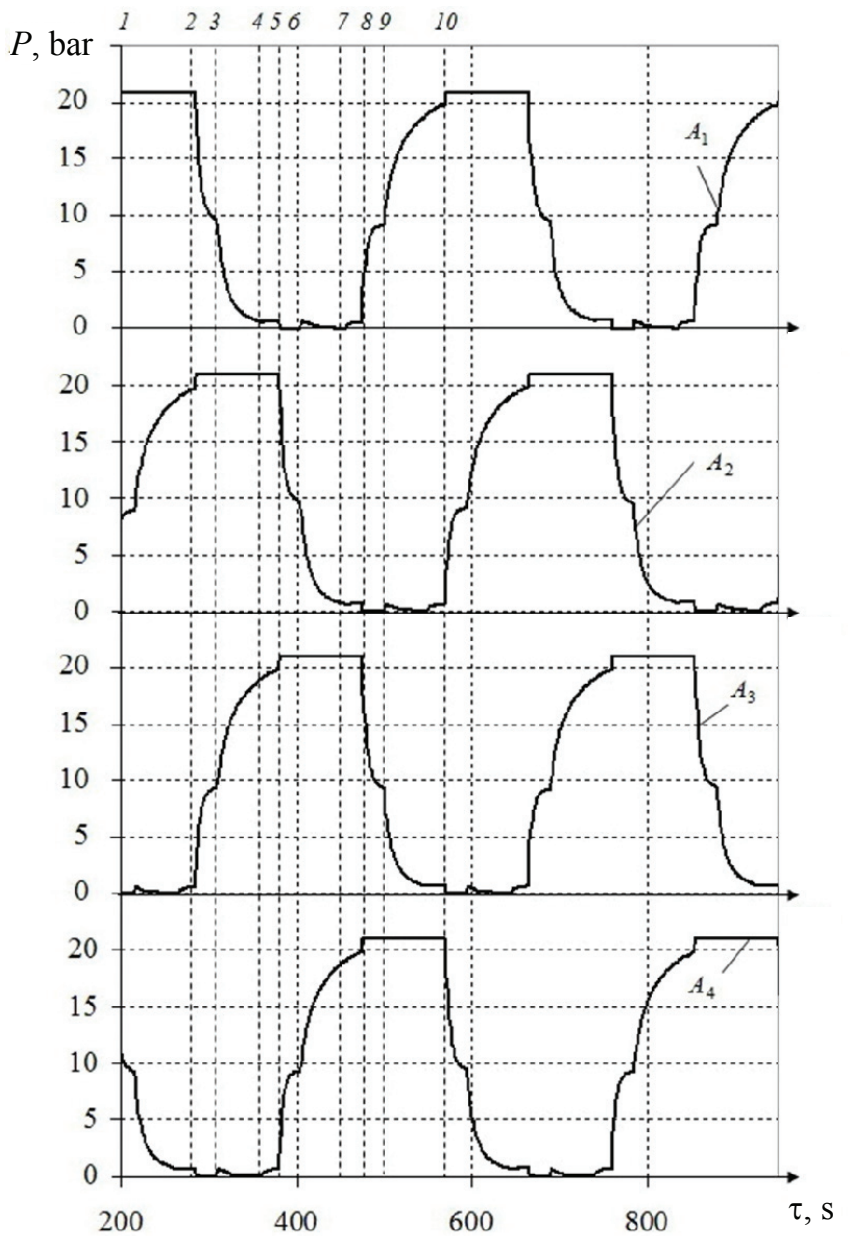

Fig. 5. Pressure dynamics in adsorbers $A_{1}-A_{4}$

At point 5, gas supply from adsorber $A_{1}$ to $A_{4}$ is stopped, the rest of the gas from $A_{1}$ is discharged into the atmosphere, the excess gas pressure in it drops to zero (segment 5-6).

The adsorbent regeneration in $A_{1}$ starts at point 6 . The production gas from adsorber $A_{2}$ is fed with counterflow into adsorber $\mathrm{A}_{1}$ and reduces the gas pressure therein. The purge ends at point 7 , then the pressure in adsorber $A_{1}$ begins to increase, and in $A_{2}$ it falls (segment 7-8).

In segment 8-9, further pressure rise in $A_{1}$ is produced by the gas from adsorber $A_{3}$, in which the pressure decreases.

In the last section 9-10, the pressure in adsorber $A_{1}$ is brought to the working pressure of adsorption by feeding the initial gas mixture, after which the cycle is repeated.

Similarly, time-shifted cyclic adsorptiondesorption processes are carried out in adsorbers $A_{2}$, $\mathrm{A}_{3}$ and $\mathrm{A}_{4}$.

The analysis of the graphs in Fig. 6, a shows that with increasing $y_{2}^{\text {in }}$ the concentration $y_{1}^{\text {out }}$ decreases. So at $y_{2}^{\text {in }}=34 \%$ vol. in a time interval $50 s \leq \tau_{\text {ads }}>125 s$ the concentration of production 

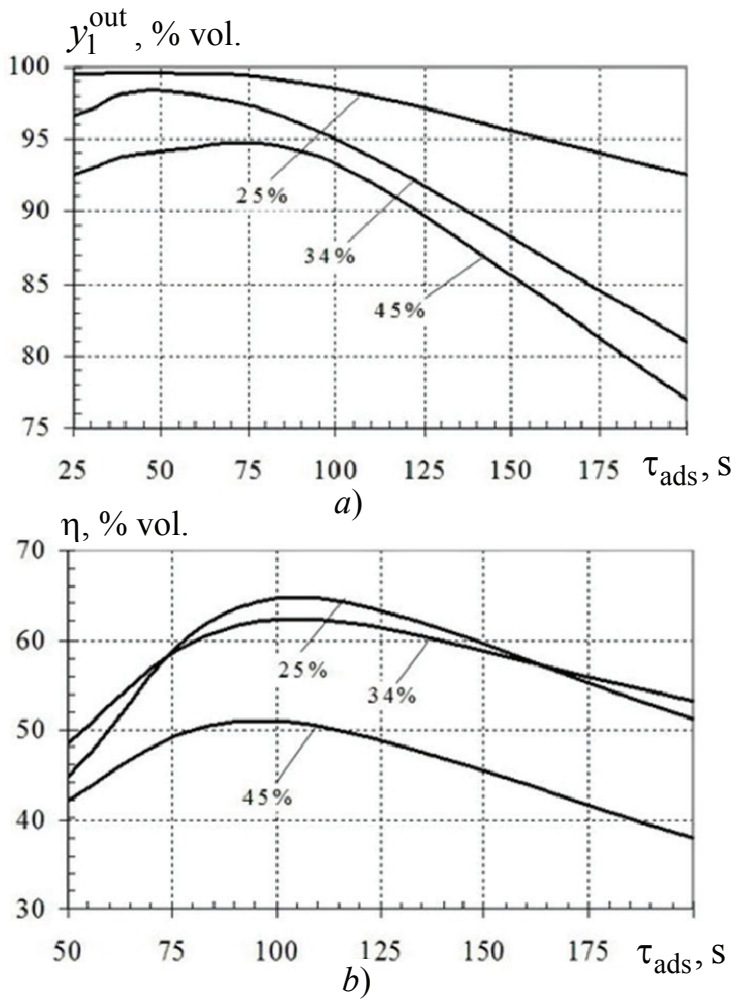

Fig. 6. Dependences $y_{1}^{\text {out }}$ and $\eta$ on $\tau_{\text {ads }}$ at $\gamma=0.5$, the temperature of the initial mixture $T_{\mathrm{g}}^{\text {in }}=30{ }^{\circ} \mathrm{C}$ and $y_{2}^{\text {in }}=25,34$ and $45 \%$ vol., respectively

hydrogen $y_{1}^{\text {out }}$ decreases from $98 \%$ vol. to $80 \%$ vol. The maximum value $y_{2}^{\text {out }} \approx 99.7 \%$ vol. is reached at $\tau_{\text {ads }} \approx 50$ s and $y_{2}^{\mathrm{In}}=25 \%$ vol.

As can be seen from the graphs in Fig. 6, $b$, the dependence of the degree of hydrogen extraction $\eta$ on the duration of the adsorption stage is also of extreme nature. The maximum degree of extraction $\eta$ according to the graph is reached at $\tau_{\mathrm{ads}} \approx 100 \mathrm{~s}$ and $y_{2}^{\text {in }}=25 \%$ vol. The increase in $y_{2}^{\text {in }}$ concentration leads to $\eta$ decrease, while the sensitivity of $\eta$ to a change in $y_{2}^{\text {in }}$ also increases.

From the analysis of the graphs in Fig. 7, $b$ it follows that the dependencies are extreme. The maximum purity of the product with $\mathrm{CO}_{2}$ content $y_{2}^{\text {in }}=45 \%$ is observed at $\approx 0.75 \mathrm{MPa}$. With a decrease in the fraction of $\mathrm{CO}_{2}$ in the initial mixture, the maximum shifts to the right; at $y_{2}^{\text {in }}=25 \%$ the graph practically becomes a kind of the saturation curve.

The concentration $y_{1}^{\text {out }}$ of production hydrogen $\mathrm{H}_{2}$ is inversely proportional to the output at all the considered temperatures and $\mathrm{CO}_{2}$ concentrations in the initial gas mixture (not shown in the Fig. 7). An increase in the productivity $G_{\mathrm{H}_{2}}^{\text {out }}$ of the PSA unit results in the desorption of the adsorbate, being insufficiently produced during the regeneration stage,
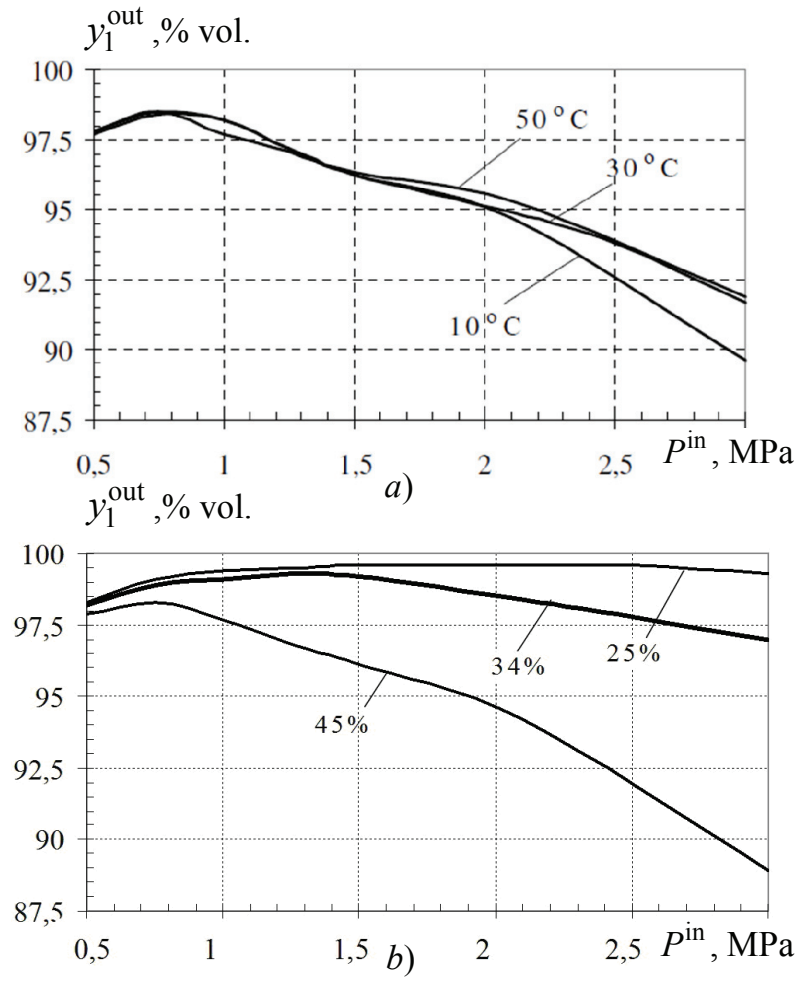

Fig. 7. Dependence $y_{1}^{\text {out }}$ on $P^{\text {in }}$ at $\tau_{\text {ads }}=50 \mathrm{~s}$ and $\gamma=0.5$ :

$a-y_{2}^{\text {in }}=34 \%$ vol., $T_{\mathrm{g}}^{\text {in }}=10,30,50{ }^{\circ} \mathrm{C}$, respectively;

$b-T_{\mathrm{g}}^{\text {in }}=30{ }^{\circ} \mathrm{C}, y_{2}^{\text {in }}=25,34,45 \%$ vol., respectively

which leads to a decrease in the absorption capacity of the adsorbent and the purity of the product obtained. For small values of productivity $G_{\mathrm{H}_{2}}^{\text {out }}$, the purity of the product is practically constant and equal to its limiting value for these conditions, the curves tend to saturate, and for values of productivity $G_{\mathrm{H}_{2}}^{\text {out }}$ above a certain threshold $y_{1}^{\text {out }}$ they start to decrease noticeably (the dependence is practically linear), and the value of this threshold depends on $T_{\mathrm{g}}^{\text {in }}$. At $T_{\mathrm{g}}^{\text {in }}=50^{\circ} \mathrm{C}$ the productivity $G_{\mathrm{H}_{2}}^{\text {out }}$ is $550 \cdot 10^{-5} \mathrm{~m}^{3} / \mathrm{s}$, at $T_{\mathrm{g}}^{\text {in }}=10,30^{\circ} \mathrm{C}-$ $250 \cdot 10^{-5} \mathrm{~m}^{3} / \mathrm{s}$.

The greatest sensitivity $y_{1}^{\text {out }}$ to a change in PSA unit output $G_{\mathrm{H}_{2}}^{\text {out }}$ is observed at $y_{2}^{\text {in }}=45 \%$ vol., and at $y_{2}^{\text {In }}=25 \%$ vol., a decrease in $y_{1}^{\text {out }}$ is insignificant. This means that an increase in $T^{\text {in }}$ in some limits or a decrease in $y_{2}^{\text {in }}$ of up to $25 \%$ vol. can significantly improve the unit's output $G_{\mathrm{H}_{2}}^{\text {out }}$ with little or no reduction in $y_{1}^{\text {out }}$.

Temperature $T_{\mathrm{g}}^{\text {out }}$ of the production $\mathrm{H}_{2}$ is proportional to the unit output $G_{\mathrm{H}_{2}}^{\text {out }}$ at all the considered values of $y_{2}^{\text {in }}$ (the dependence is not shown in the Figure). The highest value of $T_{\mathrm{g}}^{\text {out }}=323 \mathrm{~K}$ is observed at $y_{2}^{\text {in }}=45 \%$ vol., which is explained by the high 
values of $\mathrm{CO}_{2}$ concentration in the adsorbent and, as a consequence, by the large thermal effect of the adsorption process. With a decrease in the portion of the impurity in the initial gas, $T_{\mathrm{g}}^{\text {out }}$ falls, at $y_{2}^{\text {in }}=25 \%$ vol. the lowest sensitivity $T_{\mathrm{g}}^{\text {out }}$ to the PSA unit output $G_{\mathrm{H}_{2}}^{\text {out }}$ is observed.

Figure $8, a, b$ demonstrates the graphs of the change in the sorption value $a_{2}$ and $\mathrm{CO}_{2}$ concentration in the gas phase along the height of the adsorbent bed at the adsorption stage at the temperature of the initial mixture $T_{\mathrm{g}}^{\mathrm{in}}=30{ }^{\circ} \mathrm{C} ; y_{2}^{\text {in }}=34 \%$ vol.; $\gamma=0.5$ and the adsorption cycle time $\tau_{\mathrm{ads}}=20,40,60,80,100 \mathrm{~s}$, respectively.

At the initial moment of time, intensive absorption of $\mathrm{CO}$ and $\mathrm{CO}_{2}$ impurities occurs in the adsorbent's front bed, and then the mode of parallel transfer of the sorption and thermal fronts along the adsorbent bed starts. As can be seen in the Figures, the sorption front of each component is rather strongly "blurred" along the bed, which is related to the mechanism of adsorption of gas mixture components on the $\mathrm{CaA}$ zeolite.

Figure 9, $a, b$ shows the graphs of temperature variation of the adsorbent $T_{a}$ and the gas velocity $v_{\mathrm{g}}$ along the height of the adsorbent bed in the adsorption stage for different values of the adsorption cycle time $\tau_{\text {ads. }}$. During the adsorption, an intensive adsorption of adsorbate $\left(\mathrm{H}_{2}, \mathrm{CO}_{2}, \mathrm{CO}\right)$ and heat release take place in the front adsorbent bed, which leads to a significant increase in the adsorbent temperature up to $328-348 \mathrm{~K}$.
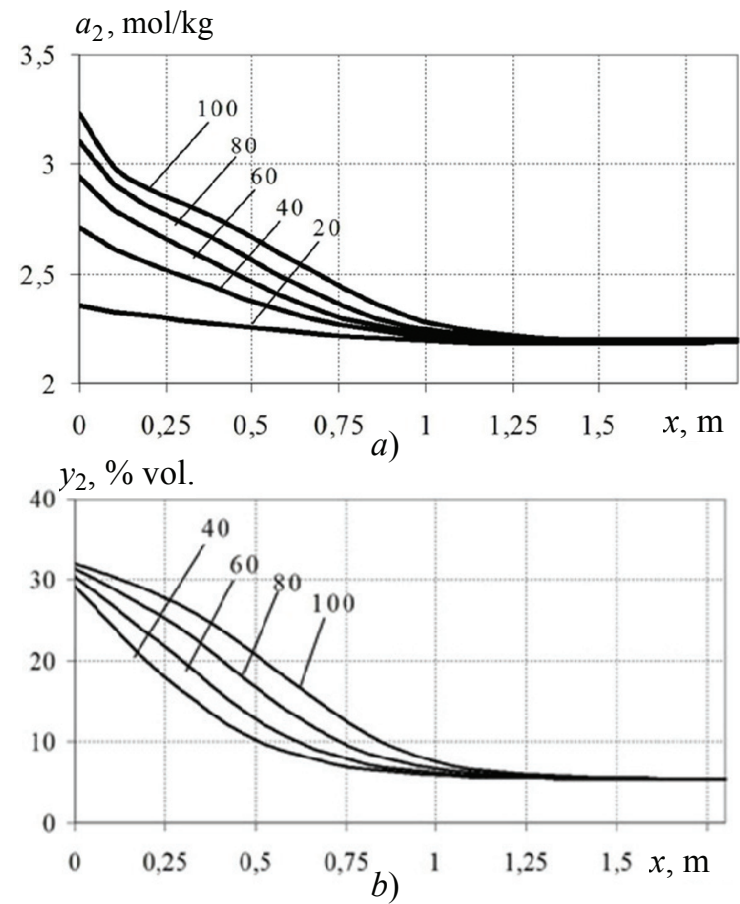

Fig. 8. Change in concentration $a_{2}, y_{2}$ along the height of the adsorbent bed

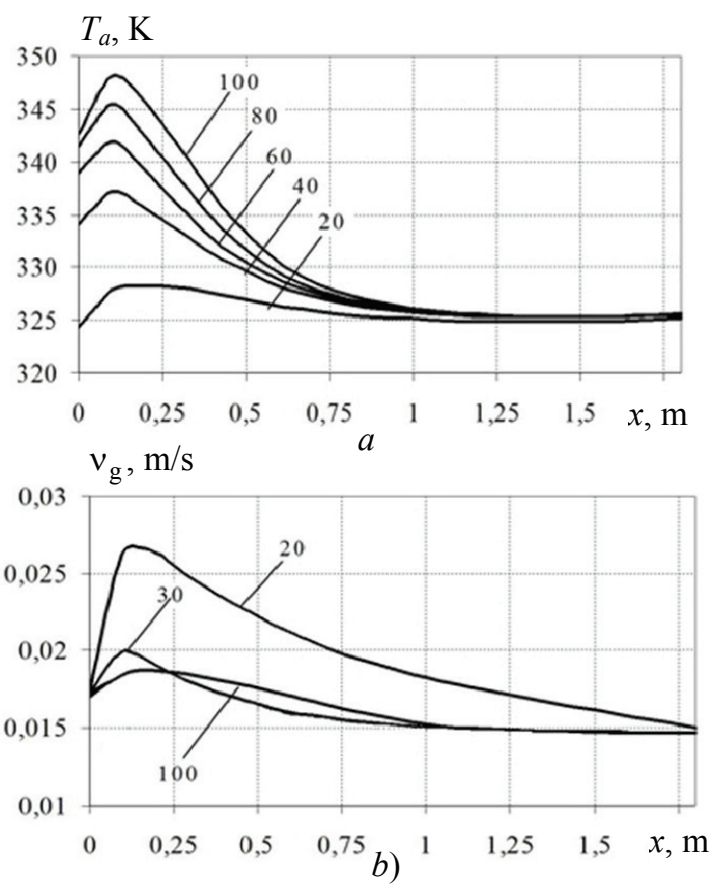

Fig. 9. Variation in the adsorbent temperature and gas mixture velocity along the height of the bed during the adsorption stage at values of the adsorption cycle time: $a-\tau_{\mathrm{ads}}=20,40,60,80,100 \mathrm{~s} ; b-\tau_{\mathrm{ads}}=20,30,100 \mathrm{~s}$

The temperature curves (Fig. 9, a) have maximum at some distance from the start of the adsorbent bed, which is explained by the transfer of sorption heat due to the convective flow in the direction of gas motion. The thermal front for the indicated moments of time moves along with the sorption one (Fig. 8). Thus, the heat losses in this mode of operation are minimal, which facilitates desorption of the adsorbate during the regeneration stage without additional adsorbent heating.

The dependence of gas mixture velocity $v_{g}$ (Fig. 9, $b$ ) on the height of the adsorbent bed is of an extreme nature, with the maximum velocity being observed in the adsorbent front bed.

The gas velocity curves in the adsorber correlate with the graphs of change in the concentration of carbon dioxide, as the main impurity, and temperature distribution of the adsorbent over the bed height. The change in the composition and temperature of the gas phase in the adsorber leads to a change in such parameters as the dynamic viscosity, density and molar mass of the gas mixture, which determine the nature of flow hydrodynamics, including the change in the gas velocity.

\section{Conclusion}

The developed mathematical model of cyclic process of adsorption separation of a gas mixture and hydrogen production can be used to achieve various 
goals: 1) to study the dynamics of adsorption processes under the action of various disturbances (uncertainties in the parameters of raw materials, technological variables) and regions of admissible modes of functioning in the space of control and disturbing actions; 2) to set and solve the problem of optimizing the process of adsorption separation of a gas mixture and obtaining hydrogen of maximum purity; 3) to develop an algorithm and adaptive control system for a cyclic process of adsorption separation of a gas mixture and hydrogen production with an operative change of tasks for regulators of an automatic control system.

On the basis of modern methods of system analysis and mathematical modeling, new scientific results have been obtained for designing automated processes and adsorption process units with cyclically changing pressure for separation of multicomponent gas mixtures.

During the computational experiments it was found that the greatest sensitivity of concentration $y_{1}^{\text {out }}$ and the degree of extraction $\eta$ of production hydrogen is observed with respect to the duration of the cycle $\tau_{\mathrm{ads}}$ of the adsorption stage, composition $y^{\text {in }}=\left(y_{1}^{\text {in }}, y_{2}^{\text {in }}, y_{3}^{\text {in }}\right)$, flow rate $G^{\text {in }}$, temperature $T_{\mathrm{g}}^{\text {in }}$ and pressure $P^{\text {in }}$ of the gas mixture at the PSA unit inlet: 1 ) the maximum concentration value $y_{1}^{\text {out }} \approx 99.7 \%$ is achieved at $\tau_{\mathrm{ads}} \approx 50 \mathrm{~s}, y_{2}^{\text {in }}=25 \%$ vol. and the temperature of the initial gas mixture $T_{\mathrm{g}}^{\text {in }}=30^{\circ} \mathrm{C}$; 2) at $T_{\mathrm{g}}^{\text {in }}=50^{\circ} \mathrm{C}$ the unit output $G_{\mathrm{H}_{2}}^{\text {out }}$ is $550 \cdot 10^{-5} \mathrm{~m}^{3} / \mathrm{s}$, and at $\left.T_{\mathrm{g}}^{\text {in }}=10,30{ }^{\circ} \mathrm{C}-250 \cdot 10^{-5} \mathrm{~m}^{3} / \mathrm{s} ; 3\right)$ the adsorbent temperature reaches its maximum value in the front bed (at $\tau_{\text {ads }}=100 \mathrm{~s}-T_{a}=348 \mathrm{~K}$, at $\tau_{\text {ads }}=20 \mathrm{~s}-$ $T_{a}=328 \mathrm{~K}$ ), and in the depth of the bed $T_{a}$ decreases to a temperature $T_{a}=325 \mathrm{~K}$ for all $\tau_{\text {ads }}$ values.

Numerical studies of the process of hydrogen production by PSA method of the separation of a multicomponent gas mixture made it possible to determine the most dangerous disturbances (composition $y^{\text {in }}=\left(y_{1}^{\text {in }}, y_{2}^{\text {in }}, y_{3}^{\text {in }}\right)$, temperature $T_{\mathrm{g}}^{\text {in }}$ and pressure $P^{\text {in }}$ of the gas mixture at the inlet of the PSA unit) and efficient control (gas mixture flow rate $G^{\text {in }}$, adsorption stage cycle duration $\tau_{\text {ads }}$ ) actions needed for setting a problem of dynamic optimization and control of the process of adsorption hydrogen production.

\section{Acknowledgement}

The work was financially supported by the Ministry of Education and Science of $R F$ within the framework of project No. 10.3533.2017.

\section{References}

1. Shumyatskiy Yu.I. Promyishlennyie adsorbtsionnyie protsessyi [Industrial adsorption processes]. M.: KolosS, 2009. 183 p. (Rus)

2. Ruthven D.M., Farooq S., Knaebel K.S. Pressure swing adsorption. New York, 1993.

3. Keltsev N.V. Osnovyi adsorbtsionnoy tehniki [Basics of adsorption technique]. M.: Himiya, 1976. 512 p. (Rus)

4. Mohamed Safdar Allie Baksh, Mark William Ackley. US Patent 6340382. Pressure swing adsorption process for the production of hydrogen, 2002.

5. Akulinin E.I., Gladyishev N.F., Dvoretskiy S.I. Perspektivnyie tehnologii i metodyi sozdaniya kompozitsionnyih sorbtsionno aktivnyih materialov dlya tsiklicheskih adsorbtsionnyih protsessov [Perspective technologies and methods for creating composite sorption active materials for cyclic adsorption processes]. TSTU Transactions, 2017, vol. 23, no. 1, pp. 85-103. (Rus)

6. Kirillin V.A., $\quad$ Syichev V.V., $\quad$ Sheyndlin A.E. Tehnicheskaya termodinamika [Technical Thermodynamics]. M.: Izd. dom MEI, 2008. 496 p. (Rus)

7. Akulov A.K. Modelirovanie razdeleniya binarnyih gazovyih smesey metodom adsorbtsii s koleblyuschimsya davleniem : dis. ... d-ra tehn. nauk 05.17.08 [Simulation of the separation of binary gas mixtures by adsorption with an oscillating pressure]. SPb.: STU, 1996. 304 p. (Rus)

8. Jeong-Geun Jee, Min-Bae Kim, Chang-Ha Lee. Adsorption characteristics of hydrogen mixtures in a layered bed: binary, ternary, and five-component mixtures. Ind. Eng. Chem. Res., 2001, vol. 40, pp. 868-878.

9. Beloglazov I.N. Osnovyi rascheta filtratsionnyih protsessov [Basics of the calculation of filtration processes]. M.: 2002. 210 p. (Rus)

10. Rid R., Praustnits Dzh., Shervud T. Svoystva gazov $i$ zhidkostey [Properties of gases and liquids]. L.: Himiya, 1982. (Rus)

11. Galperin N.I. Osnovnyie protsessyi i apparatyi himicheskoy tehnologii [Basic processes and apparatuses of chemical technology]. M.: Himiya, 1981. 812 p. (Rus)

12. Aerov M.E., Todes O.M. Gidravlicheskie $i$ teplovyie osnovyi rabotyi apparatov so statsionarnyim $i$ kipyaschim zernistyim sloem [Hydraulic and thermal foundations for the operation of devices with a stationary and boiling granular layer]. L.: Himiya, 1968. 512 p. (Rus)

13. Ishin A.A. Matematicheskoe modelirovanie $i$ upravlenie protsessom polucheniya vodoroda metodom adsorbtsionnogo razdeleniya gazovoy smesi: dis. ... kan. tehn. nauk: 05.13.06 [Mathematical modeling and control of the process of hydrogen production by the method of adsorption separation of a gas mixture]. Tambov: TSTU, 2017. 152 p. (Rus)

14. Vasilev A.S., Ishin A.A., Skvortsov S.A. Matematicheskoe modelirovanie i optimalnoe upravlenie adsorbtsionnyim protsessom razdeleniya gazovoy smesi [Mathematical modeling and optimal control of the adsorption process of gas mixture separation], Sistemyi upravleniya i informatsionnyie tehnologii [Control Systems and Information Technology], 2016, no. 4(66), pp. 47-52. (Rus) 